\title{
Diode laser versus radiofrequency treatment of the inferior turbinate - a randomized clinical trial*
}

\author{
U. Kisser ${ }^{1}$, K. Stelter ${ }^{1}$, R. Gürkov' ${ }^{1}$ M. Patscheider ${ }^{1}$, F. Schrötzlmair ${ }^{1}$, R. Bytyci', \\ C. Adderson-Kisser', A. Berghaus'1, B. Olzowy² \\ Rhinology 52: 424-430, 2014 \\ DOl:10.4193/Rhino14.001 \\ 'Department of Otorhinolaryngology, Head and Neck Surgery, University of Munich, Germany \\ *Received for publication: \\ January 2, 2014 \\ 2Department of Otorhinolaryngology, Head and Neck Surgery, University of Rostock, Germany \\ Accepted: May 28, 2014
}

\begin{abstract}
Background: Laser and radiofrequency induced volume reduction of the inferior turbinates are frequently used treatment modalities. Which of both is superior, however, is not clear to date due to a lack of controlled prospective studies. Here, we compare both methods regarding improvement of nasal breathing, complications, patient comfort and wound healing.
\end{abstract}

Methodology: Prospective, randomized, single-blinded clinical trial with intra-individual design. After randomization, one side of the nose was treated with a 940nm diode laser and the other side with bipolar radiofrequency therapy. Pre- and postoperative evaluation was performed using visual analogue scales, nasal endoscopy and objective measurements of nasal patency.

Results: Of 27 enrolled patients, 26 completed the protocol. No severe complications were observed. Intraoperative discomfort was significantly more severe on the radiofrequency side. After three months, a significant reduction of nasal obstruction was observed for laser treatment and radiofrequency therapy with no significant difference between them. Objective parameters did not improve significantly. When asked which treatment modality they would chose again $50 \%$ of the patients decided for radiofrequency treatment, $23 \%$ for laser treatment, and $19 \%$ for both.

Conclusion: DLVR and RFVR are well-tolerated treatment modalities and both significantly reduce the degree of nasal obstruction in patients with hypertrophic inferior turbinates. There was no significant difference between both treatment modalities regarding efficiency.

Key words: inferior turbinate, diode laser, radiofrequency, acoustic rhinometry, rhinomanometry

\section{Introduction}

Surgical volume reduction of the inferior turbinates can be offered to patients with chronic nasal obstruction who do not sufficiently benefit from medical treatment. If no additional surgery (e.g. septoplasty) is needed, the procedure can be performed under local anesthesia. Various different techniques have been described including electrocautery, cryosurgery, ultrasound turbinate reduction, radiofrequency and laser induced volume reduction ${ }^{(1)}$. It is still unclear, however, which method is the best for the majority of patients regarding optimal volume reduction with preservation of function. Amongst other reasons, that is because well-designed prospective studies comparing different treatment modalities are rare ${ }^{(1,2)}$. Non-contact $940 \mathrm{~nm}$ diode laser and radiofrequency induced volume reduction (DLVR and RFVR) of the inferior turbinate are two widespread, practicable and cost-effective techniques for which efficacy has been demonstrated ${ }^{(3-8)}$. As most authors only report retrospective data or data of only one method, it is difficult to compare DLVR and RFVR on the basis of existing literature ${ }^{(9)}$. The present study is the first to compare non-contact $940 \mathrm{~nm}$ DLVR and RFVR in a prospective randomized clinical trial with intraindividual design regarding improvement of nasal breathing, complications, patient comfort, and wound healing. 


\section{Materials and methods}

\section{Design}

In this prospective, randomized, single-blinded clinical trial pa-

tients with symptoms of nasal obstruction due to enlarged inferior turbinates were treated with DLVR on one side and RFVR on the other side of the nose at a tertiary referral ENT department. Drawing the lot decided whether a patient was treated with (a) DLVR on the right side and RFVR on the left side or with (b) RFVR on the right side and DLVR on the left (1:1 randomization using an envelope containing 50\% (a) lots and $50 \%$ (b) lots). Surgical treatment was performed by two experienced senior head and neck surgeons. Postoperative evaluations were done by one head and neck surgeon blinded to the treatment allocation.

\section{Eligibility}

Inclusion criteria were inferior turbinate enlargement and significant subjective bilateral improvement of nasal breathing after metazoline application. Exclusion criteria were age under 18, other reasons for nasal obstruction (e.g. chronic rhinosinusitis), inferior turbinate surgery in the past, and a rhinomanometric difference of more than $20 \%$ in nasal airflow between the left and right side after application of metazoline.

\section{Treatment}

For DLVR, a diode laser (MedTech Medilas D, wave length $\lambda=940$ $\mathrm{nm}$, Dornier MedTech GmbH, Germany) was used in a continuous wave mode at a power setting of $10 \mathrm{~W}$. Local anesthesia and decongestion were achieved by packing the turbinate with cotton wool soaked with Tetracaine (4\%) and metazoline (1:1). Laser light was applied to the turbinate in a non-contact mode as described by Janda et al. and Sroka et al. ${ }^{(5,7,10)}$ using a laser fibre guidance instrument as described by Sroka et al. ${ }^{(11)}$. For RFVR, the CelonLab ENT system and the CelonProBreath bipolar RFITT applicator (Olympus Surgical Technologies, Germany) were used at a power setting of $15 \mathrm{~W}$. After local anesthesia with superficial Tetracaine (4\%) and injection of $4 \mathrm{ml}$ lidocaine (2\%) along the periosteum of the inferior turbinate, the applicator was inserted into the head of the turbinate and pushed to its rear end before being stepwise retracted with repeated energy emission using 3D-impedance-acoustic-feedback-control as described by Seeger et al. ${ }^{(12)}$.

\section{Primary outcome measure}

The degree of nasal obstruction was evaluated before treatment, on days 1 to 21 and on day 90 after treatment using visual analogue scales (10 cm VAS). Secondary outcome measures: frequency of nasal obstruction, crust formation, secretion and itching were evaluated at the same time points using VAS. Furthermore, patient (dis)comfort and pain during surgical procedure were assessed on VAS immediately after treatment. Before treatment and on days $3,7,14,21$, and 90 , the minimal
CONSORT 2010 Flow Diagram

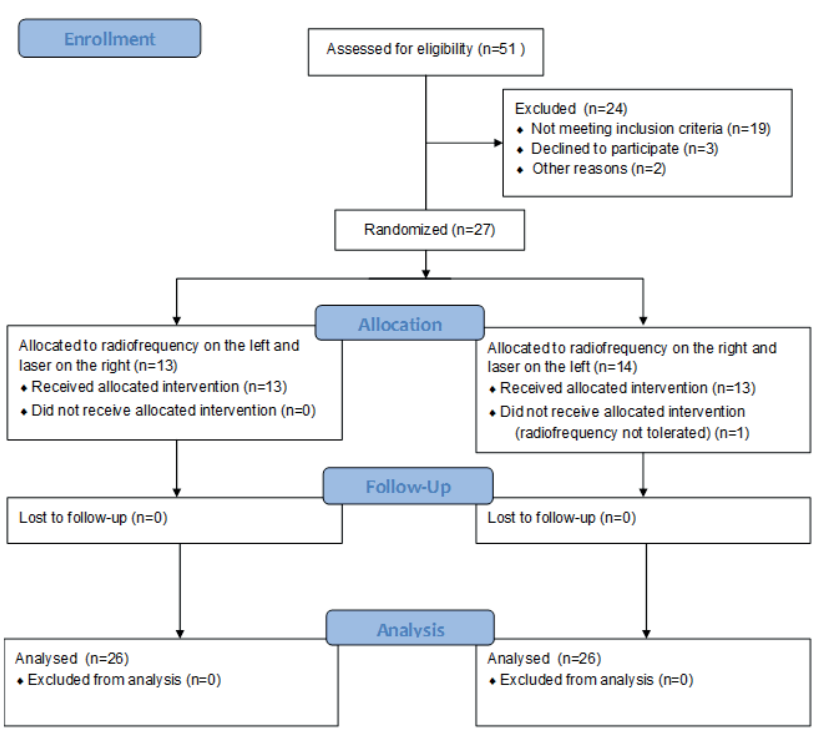

Figure 1. Patient flow diagram.

cross-sectional area (MCA2), hydraulic diameter (HD), inspiratory flow (IF) and expiratory flow (EF) were measured using acoustic rhinometry, rhinomanometry and rhinoresistometry ${ }^{(13-15)}$, and inferior turbinate swelling, crust formation and secretion were evaluated by anterior rhinoscopy and nasal endoscopy and assigned to the categories "no", "low grade", "moderate" and "severe" by a blinded investigator.

\section{Statistical analysis}

For statistical analysis SPSS software (version 22, IBM Corporation, NY, USA) was used. The paired student's t-test was used for normally distributed data and the Wilcoxon-test was used for non-normally distributed data. Distributions of categorical variables were analyzed using the chi-square test.

The study was approved by the ethics committee of the University of Munich (project number 017-08).

\section{Results}

Twenty-seven patients were included into the study. Fourteen were male and 13 female with a median age of 27 (IR: 23-46). After randomization, 14 patients received DLVR on the left and RFVR on the right side and 13 patients vice versa. One patient had to be excluded from further data collection as she did not tolerate RFVR. Twenty-six patients completed the study protocol (Figure 1). On the laser side, the mean applied energy was 754 $J( \pm 158)$. On the radiofrequency side, the mean number of punctures into the turbinate tissue was $2.7( \pm 0.7)$ and the mean number of lesions was 5.1 ( \pm 1.7$)$. 

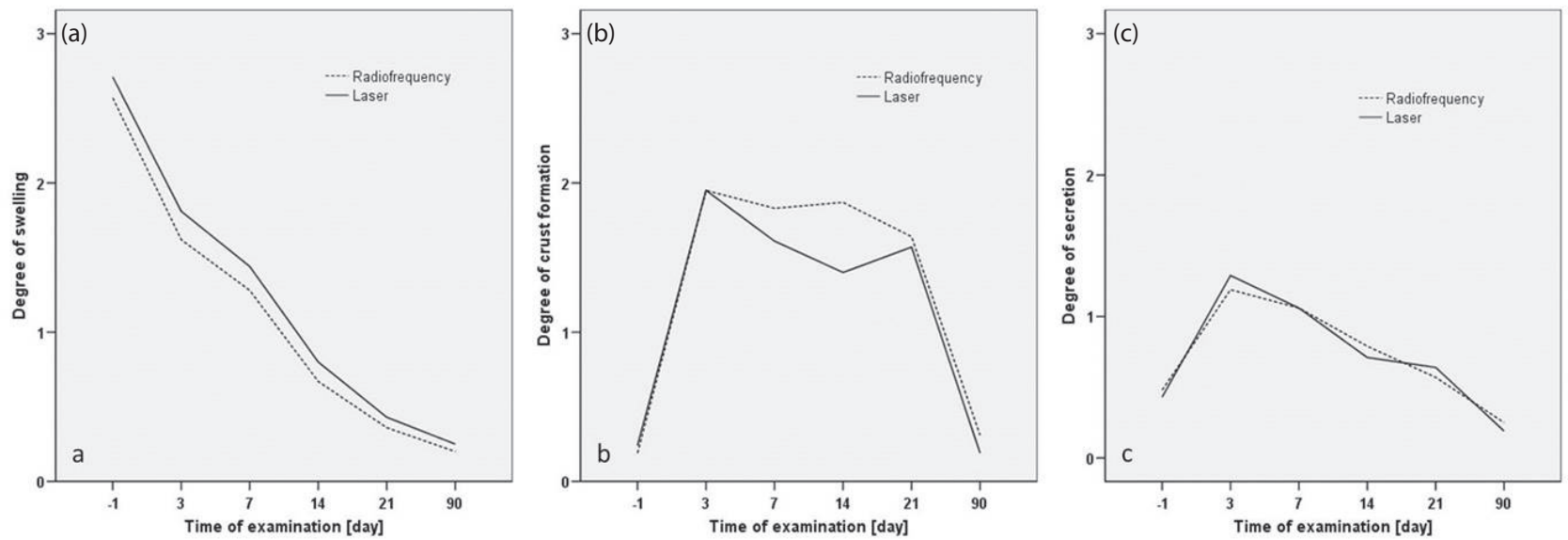

Figure 2. Evaluation of inferior turbinate swelling (a), endonasal crust formation (b) and nose secretion (c) by investigator blinded to the treatment allocation before $(-1)$ and 3, 7, 14, 21, and 90 days after laser or radiofrequency induced volume reduction; the categories on the ordinate are no (0), mild (1), moderate (2) or severe (3) symptoms; three months after treatment, a significant reduction of swelling of the inferior turbinate was observed for both treatment modalities $(p=0.00)$.

The complications that occurred during DLVR and RFVR are shown in Table 1. On VAS-rating, both overall pain and overall discomfort were low for both treatment modalities but significantly higher on the radiofrequency side $(p=0.023$ and $p=$ 0.006 , respectively; Table 2 ). Table 3 summarizes the reasons for discomfort during the surgical procedure.

Table 1. Complications during or immediately after laser and radiofrequency induced volume reduction of the inferior turbinates $(N=26)$.

\section{Laser n (\%) Radiofrequency n (\%)}

\section{Bleeding}

$0(0)$

Self-limiting bleeding

Severe pain

$1(4)$
$20(77)$

$19(95)$

$1(4)$
Table 2. Pain and discomfort during the surgical procedure were significantly higher on the radiofrequency side (VAS-rating, $\mathrm{N}=26$ ).

\begin{tabular}{|lcccc}
\hline & & Median & $\begin{array}{c}\text { Interquar- } \\
\text { tile range }\end{array}$ & p-value \\
\hline Pain & $\begin{array}{c}\text { radiofre- } \\
\text { quency }\end{array}$ & 2.0 & $0.8-4.4$ & 0.023 \\
\hline \multirow{2}{*}{ Discomfort } & $\begin{array}{c}\text { laser } \\
\text { radiofre- } \\
\text { quency }\end{array}$ & 0.8 & $0.2-2.3$ & \\
& 2.8 & $0.8-4.8$ & 0.006 \\
laser & 1.8 & $0.2-3.7$ & \\
\hline
\end{tabular}

Neither before treatment nor during the postoperative monitoring period there was a significant difference between the laser and the radiofrequency side regarding swelling of the inferior turbinates, crust formation and secretion as evaluated by a blinded investigator via anterior rhinoscopy and nasal endoscopy (Figure 2). For both treatment modalities, a significant reduction of inferior turbinate swelling could be observed after three months compared to the baseline condition $(p<0.001$, Figure

$2 a)$. Crust formation and secretion increased after the operation on both sides. Secretion continuously decreased after day three and was almost back to normal on day 14 , whereas crust formation was present beyond the three weeks period of close monitoring (Figure $2 b, c)$.

According to the questionnaires with VAS filled in by the participants, the degree of nasal obstruction was significantly lower on the radiofrequency side compared to the laser side on day 14 (difference of means (DOM) - 0.53; 95\%-CI [-1.03; -0.02]; $\mathrm{p}=$ $0.04)$. At all other time points, there was no significant difference between DLVR and RFVR regarding degree and frequency of nasal obstruction, secretion, crust formation (Figure 3a-d) and itching. Degree of nasal obstruction increased postoperatively for only one day and then gradually decreased with a significant improvement compared to the preoperative value from day 13 (RFVR, DOM 1.49; [0.21; 2.78]; $\mathrm{p}=0.025)$, and day 15 (DLVR, DOM $1.58 ;[0.35 ; 2.81] ; p=0.014$ ) on (Figure $3 b)$. After three months, the reduction of nasal obstruction was still significant for DLVR (DOM 3.93; [1.91; 5.94]; $p=0.001$ ) and RFVR (DOM 4.20; [2.28; $6,12] p=0.001)$. The frequency of nasal obstruction significantly decreased from day 8 (RFVR, DOM 2.07; [0.72; 3.42]; $p=0.005$ ) and day 7 (DLVR, DOM 1.32; [0.13; 2.52]; $p=0.031$ ) on (Figure 3a). After three months, the frequency of nasal obstruction was 

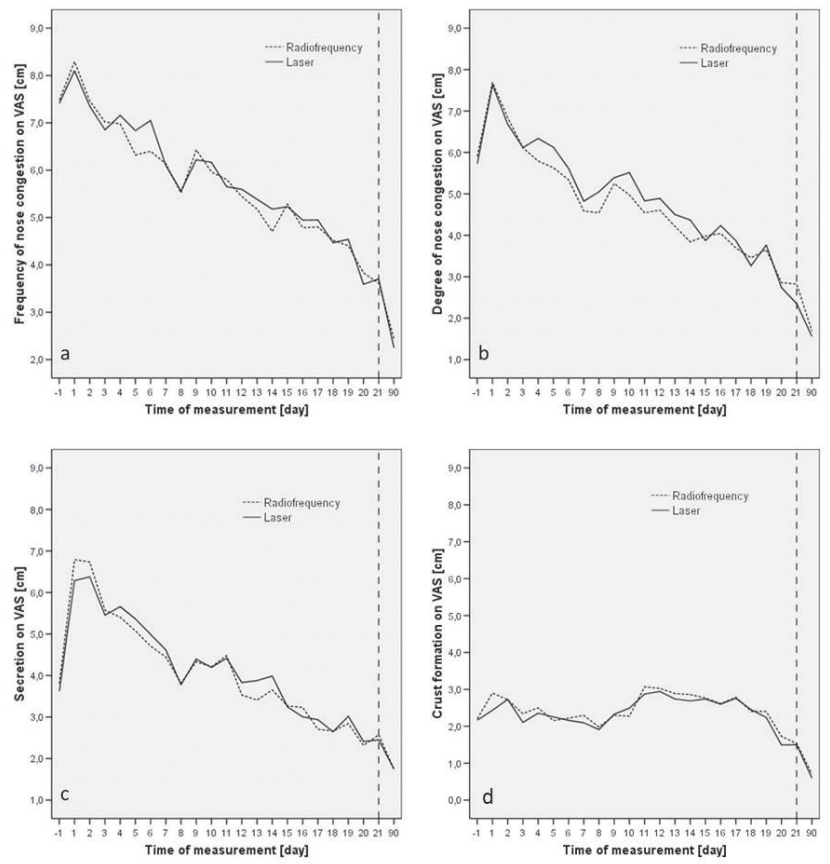

Figure 3. VAS for the first 21 days and day 90 after treatment showing a highly significant reduction of frequency ( $a, p<0.001$ for laser and RF) and degree ( $b, p=0.001$ for laser and RF) of nasal obstruction within 3 months after treatment for both laser and radiofrequency therapy; no significant change was observed for crust formation, and nasal secretion (c,d) with baseline values being comparatively low.
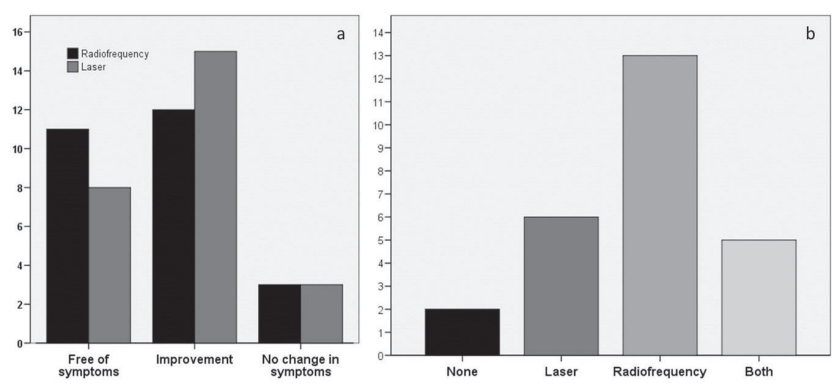

Figure 4. Patients' final assessment of laser and radiofrequency induced volume reduction of the inferior turbinate after three months $(N=26)$; most patients benefit from the therapy (a) with no significant difference between the two treatment modalities; in case of repeated treatment in the future more patients would prefer radiofrequency therapy compared to laser treatment (b).

still significantly reduced for DLVR (DOM 4.21; $[2.45 ; 5.96] ; \mathrm{p}=$ 0.000 ) and RFVR (DOM 4.09; $[2.25 ; 5.93] ; p=0.000$ ). Nose secretion and crust formation did not significantly change throughout the observation period with baseline values being comparatively low (Figure 3c, d). A significant reduction of itching was observed only on the RFVR side three months after treatment (DOM 2.03; [0.01; 4.04]; $p<0.05$ ).

At each visit, rhinomanometry, rhinoresistometry and acoustic
Table 3. Reasons for feeling of discomfort during radiofrequency or laser therapy of the inferior turbinate under local anaesthesia $(\mathrm{N}=26)$.

\begin{tabular}{|c|c|c|c|c|}
\hline & Laser & $\begin{array}{l}\text { Radiofre- } \\
\text { quency }\end{array}$ & $\begin{array}{l}\text { No speci- } \\
\text { fication }\end{array}$ & $\begin{array}{l}\text { Altoge- } \\
\text { ther }\end{array}$ \\
\hline Numbness & & & & 4 \\
\hline Bleeding & - & - & 4 & 2 \\
\hline $\begin{array}{l}\text { Pain/feeling of pres- } \\
\text { sure/heat }\end{array}$ & - & 2 & - & 5 \\
\hline Smell of burnt flesh & 1 & 4 & - & 4 \\
\hline Fear & 2 & 1 & 1 & 1 \\
\hline Urge to sneeze & - & - & 1 & 1 \\
\hline
\end{tabular}

rhinometry were conducted. There was no significant difference between the laser and the radiofrequency side regarding IF, $E F, H D$ and MCA2 at any time except on day 3 when HD was significantly higher on the radiofrequency side $(p=0.005)$. After three months, IF, HD and MAC2 had not changed significantly compared to pre-treatment values on either side. The results are shown in Table 4.

After three months, patients were asked to answer another questionnaire for a final assessment of both treatment modalities. The first question referred to the efficacy of DLVR and RFVR. Four options were offered: "free of symptoms", "improvement", "no change", and "worsening of symptoms". No patient reported a worsening of symptoms on either side. Most patients (88\%) experienced an improvement or were free of symptoms. There was no significant difference between DLVR and RFVR ( $p=0.67$, Figure 4a). When asked which treatment modality they would have repeated if it was necessary (DLVR, RFVR, both, none), $50 \%$ of the patients decided for RFVR, $23 \%$ for DLVR, $19 \%$ for both and $8 \%$ for none of the two (Figure $4 \mathrm{~b}$ ).

\section{Discussion}

The $940 \mathrm{~nm}$ diode laser was chosen for this study because its use is widespread in hospitals and medical practices and because it has been shown to yield good results ${ }^{(5,10,16)}$. The CeIonLab ENT system with its bipolar RFITT applicator was chosen because, in contrast to other systems, it allows for a controlled and standardized energy application due to its impedanceacoustic-feedback-control function. It continuously measures the impedance of the tissue during surgical treatment and automatically stops energy application when a certain impedance threshold value is reached. Another advantage of the CelonLab ENT system is that the probe is a long, slim single needle so that few insertions are needed to treat the whole length of the 
Table 4. Results of rhinomanometric, rhinoresistometric and acoustic rhinometric measurements before and three months after treatment. There was no significant difference between radiofrequency and diode laser induced volume reduction (RFVR, DLVR) regarding flow, hydraulic diam-

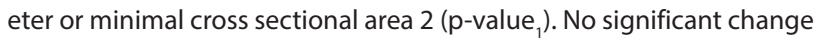
of these parameters was observed three months after treatment compared to the pre-treatment values for any of the two surgical techniques $\left(p-\right.$ value $\left._{2}\right)$. Flow was measured at a pressure level of $150 \mathrm{~Pa}$.

\begin{tabular}{|c|c|c|c|c|c|}
\hline & \multicolumn{2}{|c|}{ Pre-treatment } & \multicolumn{2}{|c|}{$\begin{array}{l}\text { 3-months-post- } \\
\text { treatment }\end{array}$} & \multirow[t]{2}{*}{$\begin{array}{c}\text { p- } \\
\text { value }_{2}\end{array}$} \\
\hline Numbness & Median & $\begin{array}{l}25 \text { th - 75th } \\
\text { percentile }\end{array}$ & Median & $\begin{array}{l}25 \text { th }-75 \text { th } \\
\text { percentile }\end{array}$ & \\
\hline \multicolumn{6}{|c|}{ Flow at inspiration $[\mathrm{ml} / \mathrm{s}]$} \\
\hline$R F V R$ & 277 & $159-497$ & 339 & $273-456$ & 0,43 \\
\hline$D L V R$ & 268 & $132-408$ & 339 & $201-474$ & 0,24 \\
\hline p-value ${ }_{1}$ & 0,77 & & 0,99 & & \\
\hline \multicolumn{6}{|c|}{ Flow at expiration [ml/s] } \\
\hline$R F V R$ & 282 & $138-382$ & 307 & $243-388$ & 0,41 \\
\hline$D L V R$ & 256 & $123-381$ & 384 & $186-469$ & 0,10 \\
\hline$p$-value ${ }_{1}$ & 0,70 & & 0.53 & & \\
\hline \multicolumn{6}{|c|}{ Hydraulic diameter [mm] } \\
\hline$R F V R$ & 4,8 & $3,8-5,1$ & 4,6 & $3,9-4,9$ & 0,78 \\
\hline$D L V R$ & 4,3 & $3,8 \neg-4,9$ & 4,9 & $4,3-5,2$ & 0,37 \\
\hline$p$-value ${ }_{1}$ & 0,52 & & 0.58 & & \\
\hline \multicolumn{6}{|c|}{ Minimal cross sectional area $2\left[\mathrm{~cm}^{2}\right]$} \\
\hline$R F V R$ & 1,5 & $1,3-2,1$ & 1,6 & $1,4-1,9$ & 0,62 \\
\hline$D L V R$ & 1,2 & $1,1-2,9$ & 1,6 & $1,2-1,8$ & 0,21 \\
\hline$p$-value ${ }_{1}$ & 0,27 & & 0.72 & & \\
\hline
\end{tabular}

turbinate minimizing trauma for the mucosal surface.

A reliable blinding was only possible for the surgeon who did the postoperative evaluations but not for the patient who can easily distinguish between the non-contact laser procedure and the radiofrequency treatment, which involves injection of local anaesthetics and introduction of the probe into the inferior turbinate. Interestingly, however, a considerable proportion of patients did not remember which technique was used on which side of the nose when they came to postoperative care, especially after three months. The intraindividual design of this study allows for a more reliable exclusion of unknown and unequally distributed confounders affecting the outcome variables than an interindividual design.

Both laser and radiofrequency induced volume reduction have been successfully used for inferior turbinate surgery ${ }^{(1-3,5-8,8,10,12,16-}$

19). They increase the local tissue temperature causing fibrosis with wound contraction leading to volume reduction. A major difference between the two methods is that radiofrequency energy is applied inside the soft tissue without significantly affecting the mucosal surface ${ }^{(20-24)}$ whereas diode laser energy is applied superficially potentially impairing the integrity of the mucosa and the function of its ciliae. Microscopic studies of $\mathrm{CO}_{2}$-laser-treated mucosa have demonstrated that the ciliated epithelium is damaged and regenerates only to a limited degree ${ }^{(25,26)}$. Accordingly, Sapci et al. found that the mucociliary transport time was significantly higher after $\mathrm{CO}_{2}$-laser treatment of the inferior turbinate compared to RFVR or no treatment (27). Thus, one might expect that DLVR is associated with prolonged healing and more postoperative complaints such as crusting, secretion and, consequently, nasal obstruction. However, the studies mentioned above refer to $\mathrm{CO}_{2}$-laser treatment. Other authors used Ho:YAG lasers and diode lasers, respectively, and report that mucociliary function tests six months and one year after treatment showed no significant variation in comparison to the preoperative measurements ${ }^{(10,28)}$. In the present study both physical examination and patients' feedback on VAS consistently show that there is no substantial difference between DLVR and RFVR regarding the healing process and the inconveniences it involves (Figures 2,3).

Three months after surgery, patient feedback (VAS) and evaluation by the blinded investigator revealed a significant reduction of obstructive symptoms and of swelling of the inferior turbinate, respectively, compared to the preoperative state (Figures 2,3) for both DLVR and RFVR. Thus, both treatment modalities can efficiently improve nasal breathing. Again, there was no significant difference between DLVR and RFVR.

The results of rhinomanometry, rhinoresistometry and acoustic rhinometry were not consistent with the observations made by the blinded investigator and the patients' feedback on VAS which showed significant improvements. Similarly, many other studies have found a discrepancy between objective and subjective nasal obstruction and it is controversial whether objective measurements of nasal patency should be performed routinely pre- and postoperatively. In a recently published study, Braun et al. analysed the correlation of HD and MCA2 and a validated subjective symptom score (NOSE) in 24 subjects. They found only a moderate correlation before decongestion on the left side of the nose while there was no correlation on the right 
side before and on both sides after decongestion ${ }^{(15,29)}$. In a metaanalysis, André et al. came to the conclusion that the correlation between objective parameters of nasal patency and subjective sensation remains unclear and therefore there seems to be only a limited argument for the use of rhinomanometry or acoustic rhinometry for quantifying surgical results. According to André et al., the chance of a correlation between objective and subjective parameters is even smaller in patients lacking obstructive symptoms ${ }^{(30)}$ like the majority of the participants of our study after treatment. Another shortcoming of rhinomanometric, rhinoresistometric and acoustic rhinometric data is the fact that they represent only a snapshot of nasal patency which is subject to significant fluctuation during the day ${ }^{(31)}$. Most patients with inferior turbinate hyperplasia especially suffer from nightly nasal obstruction but we do not have preoperative objective values for follow-up that have been taken at night when participants were in a supine position. Interestingly, Assanasen et al. have found both a significant improvement of nasal congestion scores and objective parameters (total nasal airway resistance and total nasal airflow, measured by rhinomanometry) in patients who underwent combined RFVR and lateral outfracture of enlarged inferior turbinates. Thus, it seems reasonable to compare RFVR with combined RFVR and lateral outfracture in a prospective, randomized study with an intraindividual design ${ }^{(32)}$.

At the end of the follow-up period, the vast majority of patients reported improvement or freedom from symptoms and no patient had experienced worsening on either side. There was no significant difference between DLVR and RFVR. Thus, both DLVR and RFVR can be considered as effective therapeutic options in patients with enlarged inferior turbinates. Interestingly, when asked which treatment modality they would chose again about half of the participants preferred radiofrequency whereas only one fourth decided for the laser although directly after treatment, radiofrequency therapy had been evaluated as being more painful and uncomfortable (Table 2). This observation may in part be due to a slightly more invasive character of RFVR that might be accompanied by a stronger placebo effect. On the other hand, it might also reflect a true, slight advantage of RFVR over DLVR that is not adequately reflected by the outcome measures of our study. As a tendency, more patients reached freedom from symptoms on the radiofrequency side.

Both DLVR and RFVR can be performed well under local anesthesia causing only mild pain and discomfort (Table 2). An advantage of DLVR is the non-contact technique, which allows treatment without bleeding and makes the procedure less uncomfortable for the patient. In contrast, RFVR is often associated with bleeding, mostly caused by the injection of local anesthetics. This bleeding, however, is quickly self-limiting in most cases and only two patients rated it as reason for discomfort during the procedure (Table 1). An advantage of RFVR is an easier handling of the biopolar needle-like radiofrequency probes compared to the diode laser fibre. The radiofrequency applicator can be pushed to the rear end of the concha and is then stepwise retracted for repeated energy emission. In most cases the whole length of the turbinate can be reached whereas it is often difficult to work on the posterior end of the turbinate with the non-contact diode laser fibre. Acoustic-impedance feedback and auto stop function make it easier to achieve a standardized treatment effect, while the effect of the laser in the non-contact mode has to be optically controlled and can vary widely depending on light dispersion on the tip of the fibre, angle between laser beam and tissue and distance between fibre tip and tissue. Finally, fewer special safety measures have to be taken for the radiofrequency treatment compared to laser treatment.

\section{Conclusion}

DLVR and RFVR are similarly effective and well-tolerated treatment modalities and both significantly reduce the degree of nasal obstruction in patients with hypertrophic inferior turbinates. RFVR is more painful during the procedure but a majority of patients would prefer it over DLVR if a revision volume reduction became necessary.

\section{Acknowledgements}

This study was financially supported by Olympus Surgical Technologies Europe, Celon AG medical instruments, Teltow, Germany. Olympus provided expense allowances for patients, the fee for the ethics committee, and radiofrequency probes.

\section{Authorship contribution}

UK: patient enrolment, pre- and postoperative clinical evaluations, preparation of manuscript; KS: surgical treatment, manuscript review; RG: patient enrolment, preparation of manuscript, manuscript review; MP: patient enrolment, preparation of manuscript, manuscript review; FS: patient enrolment, preparation of manuscript, manuscript review; RB: postoperative follow-up, pre- and postoperative clinical evaluations; CA-K: statistical analyses, figures, tables; $A B$ : manuscript review; application for ethical approval; BO: study design, application for ethical approval, principal investigator, surgical treatment, preparation of manuscript

\section{Conflicts of Interest}

None 


\section{References}

1. Hol MKS, Huizing EH. Treatment of inferior turbinate pathology: a review and critical evaluation of the different techniques. Rhinology. 2000; 38: 157-166.

2. Jackson LE, Koch RJ. Controversies in the management of inferior turbinate hypertrophy: a comprehensive review. Plast Reconstr Surg. 1999; 103: 300-312.

3. Barbieri M, Salami A, Mora F, et al. High frequency surgery in the treatment of turbinate hypertrophy: 11 years' experience. Acta Otorhinolaryngol Ital. 2003; 23: 436-439.

4. Farmer SEJ, Quine SM, Eccles R. Efficacy of inferior turbinate coblation for treatment of nasal obstruction. JLO. 2009; 123: 309-314

5. Janda P, Sroka R, Baumgartner R, Grevers G, Leunig A. Laser treatment of hyperplastic inferior nasal turbinates: A review. Lasers Surg Med. 2001; 28: 404-413.

6. Maskell S, Eze N, Patel P, Hosni A. Laser inferior turbinectomy under local anaesthetic: a well tolerated out-patient procedure. JLO. 2007; 121: 957-961.

7. Sroka R, Janda P, Killian T, Vaz F, Betz CS Leunig A. Comparison of long term results after Ho:YAG and diode laser treatment of hyperplastic inferior nasal turbinates. Lasers Surg Med. 2007; 39: 324-431.

8. Porter MW, Hales NW, Nease CJ, Kremp GA. Long-term results of inferior turbinate hypertrophy with radiofrequency treatment: a new standard of care? Laryngoscope. 2006; 116: 554-557.

9. Famer SE, Eccles R. Understanding electrosurgery for the treatment of nasal turbinate enlargement. JLO. 2007; 121: 615-622.

10. Janda P, Sroka R, Tauber S, Baumgartner R, Grevers G, Leunig A. Diode laser treatment of hyperplastic inferior nasal turbinates. Lasers Surg Med. 2000; 27: 129-139.

11. Sroka R, Roesler P, Janda P, Grevers G, Leunig A. Endonasal laser surgery with a new laser fibre guidance instrument. Laryngoscope. 2000; 110: 332-334.

12. Seeger J, Zenev E, Gundlach P, Stein T, Muller G. Bipolar radiofrequency-induced thermotherapy of turbinate hypertrophy: pilot study and 20 months follow-up. Laryngoscope. 2000; 113: 130-135.

13. Mlynski G, Beule A. Diagnostic methods of nasal respiratory function. HNO. 2008; 56: 81-99.
14. Clement PA, Gordts F. Consensus report on acoustic rhinometry and rhinomanometry. Rhinology. 2005; 43: 169-179.

15. Braun T, Rich M, Kramer MF. Hydraulic diameter, minimal cross-sectional area and NOSE score: correlation of three variables describing nasal patency. Braz J Otorhinolaryngol. 2013; 79: 354-358

16. Havel M, Sroka R, Leunig A, Patel P, Betz C: A double-blind randomized, intra-individual controlled feasibility trial comparing the use of 1,470 and $940 \mathrm{~nm}$ diode laser for the treatment of hyperplastic inferior nasal turbniates. Lasers Surg Med. 2011; 43: 881886.

17. Oswal V, Bingham B. A pilot study of the Holmium:YAG laser in nasal turbinate and tonsil surgery. J Clin Las Med Surg. 1992; 10:211-216.

18. Lippert B, Werner J. CO2 laser surgery of hypertrophied inferior turbinates. Rhinology. 1997; 35: 33-36.

19. Dilkes M, Cameron I, Quinn S, Kenyon G. Preliminary experience with an $810 \mathrm{~nm}$ wavelength diode laser in ENT surgery. Laser Med Sci. 1994; 9::261-264.

20. Nease C, Krempl G. Radiofrequency treatment of turbinate hypertrophy: a randomized, blinded, placebo-controlled clinical trial. Otolaryngol Head Neck Surg. 2004; 130: 291-299.

21. Li KK, Powell NB, Riley RW, Troell RJ, Guilleminault C. Radiofrequency volumetric tissue reduction for treatment of turbinate hypertrophy: a pilot study. Otolaryngol Head Neck Surg 1998; 119: 569-573.

22. Coste A, Yona L, Blumen $M$, et al. Radiofrequency is a safe and effective treatment of turbinate hypertrophy. Laryngoscope. 2001; 111: 894-899.

23. Rhee CS, Kim DY, Won TB, et al. Changes of nasal function after temperature-controlled radiofrequency tissue volume reduction for the turbinate. Laryngoscope. 2001; 111: 153-158.

24. Elwany S, Gaimaee R, Fattah HA Radiofrequency bipolar submucosal diathermy of the inferior turbinates. Am J Rhinol. 1999; 13: 145-149.

25. Elwany S, Abdel-Moneim MH. Carbon dioxide laser turbinectomy. An electron microscopic study. J Laryngol Otol. 1997; 111 . 931-934.
26. Kubota I. Nasal function following carbon dioxide laser turbinate surgery for allergy. Am J Rhinol. 1995; 9: 155-161.

27. Sapci T, Sahin B, Karavus A, Akbulut UG. Comparison of the effects of radiofrequency tissue therapy, CO2 laser therapy, and partial turbinectomy applications on nasal mucociliary functions. Laryngoscope. 2003; 133: 514-519.

28. Leunig A, Janda P, Sroka R, Baumgartner R, Grevers G. Ho:YAG laser treatment of hyperplastic inferior nasal turbinates. Laryngoscope. 1999; 109: 1690-1695.

29. Stewart MG, Witsell DL, Smith TL, Weaver EM, Yueh B, Hannley MT. Development and validation of the Nasal Obstruction Symptom Evaluation (NOSE) scale. Otolaryngol Head Neck Surg. 2004; 130 157-163.

30. André RF, Vuyk HD, Ahmed A, Graamans K, Nolst Trenité GJ. Correlation between subjective and objective evaluation of the nasal airway. A systematic review of the highest level of evidence. Clin Otolaryngol. 2009; 34: 518-525.

31. Eccles R. The central rhythm of the nasal cycle. Acta Otolaryngol. 1978; 86: 464-468.

32. Assanasen P, Banhiran W, Tantilipikorn P, Pinkaew B. Combined radiofrequency volumetric tissue reduction and lateral outfracture of hypertrophic inferior turbinate in the treatment of chronic rhinitis: short-term and long-term outcome. Int Forum Allergy Rhinol. 2014; 4: 339-344

\section{Ulrich Kisser}

Department of Otorhinolaryngology

Head and Neck Surgery

University of Munich

Marchioninistraße 15

81377 Munich

Germany

Tel: +49 897095 0;

Fax: +49897095 5864

E-mail: Ulrich.Kisser@med.uni-muenchen.de 